\title{
IPSS Risk Score 0
}

National Cancer Institute

\section{Source}

National Cancer Institute. IPSS Risk Score O. NCI Thesaurus. Code C139297.

An International Prognostic Scoring System for Myelodysplastic Syndrome risk score of

0 , corresponding to low risk. 